\title{
Expiratory Flow Limitation in Obstructive Sleep Apnea and COPD: A Quantitative Method to Detect Pattern Differences Using the Negative Expiratory Pressure Technique
}

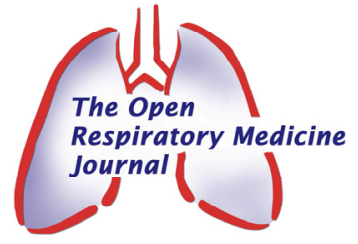

\author{
Ahmet Baydur ${ }^{*}$, , Cheryl Vigen ${ }^{2}$ and Zhanghua Chen $^{3}$ \\ ${ }^{1}$ Division of Pulmonary and Critical Care Medicine, Keck School of Medicine, University of Southern California (USC), \\ USA \\ ${ }^{2}$ Department of Occupational Therapy, Herman Ostrow School of Dentistry of USC, ${ }^{3}$ Department of Preventive \\ Medicine, Keck School of Medicine, USC, Los Angeles CA, 90033, USA
}

\begin{abstract}
Background: Expiratory flow limitation (EFL), determined by the negative expiratory pressure (NEP) technique, can exhibit overlapping patterns in COPD, obstructive sleep apnea (OSA) and non-OSA obesity. We assessed the ability of a quantitative method to assess EFL to discriminate COPD from obese and OSA patients during NEP (-2 to $3 \mathrm{~cm} \mathrm{H}_{2} \mathrm{O}$ ) testing.

Methods: EFL was quantified by measuring the area under the preceding control tidal breath (Vt) subtended by the NEP curve (\%AUC). To quantify mean lost flow, the ratio of \%AUC to percentage of control Vt over which EFL occurred $(\%$ EFL) $(=\%$ AUC $/ \%$ EFL) was computed. Percent EFL, \%AUC, and \%AUC/\%EFL was compared in 42 patients with COPD, 28 obese subjects without OSA, 50 with OSA (26 mild-moderate, 24 severe) and 19 control subjects, in seated and supine postures.

Results: All patients exhibited \%EFL values significantly higher than control subjects, corrected for age and gender (ANOVA). All but the COPD group exhibited higher \%EFL while supine, but not \%AUC or \%AUC/\%EFL. Amongst seated subjects, \%EFL was highest in COPD, and amongst supine groups, it was greatest in OSA and COPD. $\% \mathrm{AUC} / \% \mathrm{EFL}$ was significantly higher in mild-moderate OSA than in COPD only while seated. \%AUC or \%AUC/\%EFL did not discriminate amongst other cohorts in either posture.

Conclusions: Computation of \%EFL helps distinguish EFL in COPD, obese and OSA patients from those of control subjects. Computation of \%AUC and \%AUC/\%EFL is useful in determining the magnitude of extrathoracic FL in individuals with obesity and OSA, but does not distinguish between cohorts.
\end{abstract}

Keywords: Negative expiratory pressure, sleep apnea, COPD.

\section{INTRODUCTION}

The major factor contributing to the generation of sleep disordered breathing is increased upper airway collapsibility [1-4]. Assessment of flow dynamics during expiration should provide information about the degree of airway collapsibility. Expiratory flow limitation (EFL) during quiet breathing in various respiratory disorders can be demonstrated by the negative expiratory pressure (NEP) technique [5-9]. In chronic obstructive pulmonary disease (COPD), EFL is defined as absence of change in expiratory flow during application of NEP, and is a clinically important factor contributing to dyspnea by leading to hyperinflation and inspiratory muscle dysfunction. To date, no study has questioned the reliability and accuracy of the NEP technique [10]. It can be easily detected during quiet breathing using

*Address correspondence to this author at the Division of Pulmonary and Critical Care Medicine, Keck School of Medicine, University of Southern California, IRD 723, 2020 Zonal Avenue, Los Angeles, CA 90033, USA; Tel: 323-226-7923; Fax: 323-226-7238; E-mail: baydur@usc.edu the NEP method, a simple, noninvasive test performed without discomfort to the patient. Tidal EFL detected by the NEP method has been shown to correlate more closely with the sensation of dyspnea than $\mathrm{FEV}_{1}$ [11].

The NEP technique has also been used to assess upper airway collapsibility in patients with OSA, in which EFL has been described as a transient or sustained decrease in expiratory flow (frequently below the control tidal expiratory flow) during application of NEP [7-9, 12-16]. Dyspnea in obese individuals is related to increased work of breathing due to a decrease in FRC with resultant increase in intrathoracic EFL and intrinsic positive end-expiratory pressure (PEEPi), increased respiratory drive, and intermittent narrowing or collapse of the upper airway, made worse upon assuming the supine position [17].

Since dyspnea is common in patients with COPD and morbid obesity (many of whom have OSA), and is related to the presence of EFL, use of the NEP method in these disorders is of clinical importance in helping distinguish the forms of EFL occurring in these populations. It is sometimes 
difficult, however, to distinguish EFL in OSA from that observed in COPD (as defined by Koulouris et al. [5]) because patients may exhibit EFL patterns combining features of both conditions. The purpose of this study was to compare and assess the ability of the NEP technique to distinguish individuals with COPD from those with OSA and non-OSA obesity by analyzing the type of EFL using a modification of a previously described method [14]. In particular, we were interested in the discriminating ability of the NEP method to separate cohorts from each other by analyzing their EFL characteristics.

\section{METHODS}

\section{Subjects}

We screened 145 subjects in the pulmonary function laboratory on the same day as they underwent lung function testing, from April 2006 to July 2008. A questionnaire concerning medical and smoking history and respiratory symptoms was administered. The diagnosis of COPD was made according to European Respiratory Society recommendations [18].

The diagnosis of OSA was confirmed in obese patients by standard overnight polysomnography according to criteria of the American Academy of Sleep Medicine [19]. The subjects were divided into those with mild-moderate OSA (apnea-hypopnea index, AHI $=5-30$ ), and those with severe OSA (AHI $\geq 30$ ) [20]. A BMI of $\geq 30$ was classified as obese [21]. Subjects were excluded if they had otolaryngological defects, use of hypnotic medications, asthma, or any acute cardiorespiratory disease. COPD patients and control subjects were excluded if they had symptoms of sleep apnea, and thus did not undergo sleep studies. Control subjects were individuals free of cardiorespiratory illness. The study was approved by the Institutional Review Board of the University of Southern California Health Sciences Campus, and an informed consent was obtained from each patient (IRB Proposal \# HS-05-00412). The findings of this study were, in part, previously reported in abstract form [22].

\section{Pulmonary Function Testing}

Spirometry and lung volumes by body plethysmography were performed while seated with a Collins GS/PLUS or DSII/PLUS system (Warren Collins; Braintree, MA). The cut-off point of the post-bronchodilator ratio between forced expiratory volume in 1 second $\left(\mathrm{FEV}_{1}\right)$ and forced vital capacity (FVC) COPD was 0.7 . Predicted values for $\mathrm{FEV}_{1}$, $\mathrm{FVC}$ and $\mathrm{FEV}_{1} / \mathrm{FVC}$ were from Schoenberg et al. [23], and for subdivisions of lung volume from Crapo et al. [24].

\section{Negative Expiratory Pressure (NEP) Technique}

Expiratory flow limitation (EFL) was assessed with an experimental setup (Fig. 1) as described by Valta et al. (6): A flanged rubber mouthpiece was connected in series to a heated No. 3 pneumotachograph (Fleisch; Lausanne, Switzerland) and an electromagnetically operated valve. The latter allowed rapid switching of the subject to negative pressure generated by a vacuum cleaner (Microstat; Kent; Elkhart, IN), whose power was adjusted by a variac (Ohmite Variac; Skokie, IL). The occlusion valve (Foon XP-1; McGill University; Montreal, Quebec, Canada) consisted of a spring-operated piston that remained closed and could be opened by activating the magnet with a software-generated digital signal. Flow was measured with a heated pneumotachograph and differential pressure transducer (Validyne MP-45, $\pm 2.5 \mathrm{~cm} \mathrm{H}_{2} \mathrm{O}$; Validyne; Northridge, CA). The pneumotachograph was linear over the experimental range of flow. Volume was obtained by integration of digitized flow. Pressure at the airway opening was measured through a side port on the mouthpiece using a differential pressure transducer (Validyne MP- $45, \pm 50 \mathrm{~cm}$ $\mathrm{H}_{2} \mathrm{O}$; Validyne). The pressure transducer was calibrated before and after each study with a water manometer. The flow and pressure signals, generated with Validyne CD-19 carrier demodulators (Validyne), were passed through a 32$\mathrm{Hz}$, low pass filter and sampled at $100 \mathrm{~Hz}$ with a DASO8 $12-$ bit analog-to-digital converter (Measurement Computing Corporation; Middleboro, MA). The computer used was a $25-\mathrm{MHz}$ personal computer with a 14-inch monitor. Software, written in Microsoft Quick Basic (Microsoft; Redmond, WA), provided for real-time collection and display of flow, volume and pressure data as well as operator control. The occlusion valve was driven by the computer and had an opening time of $57 \mathrm{~ms}$. It was activated when the expiratory flow reached a threshold level of $20 \mathrm{~mL} / \mathrm{s}$. Artifacts on the flow record caused by common mode rejection ratio were negligible [25].

\section{Procedure and Data Analysis}

Subjects sat in a comfortable chair at least 1 or 2 hours after eating or drinking coffee. They breathed room air through the equipment assembly with a nose clip on. Each

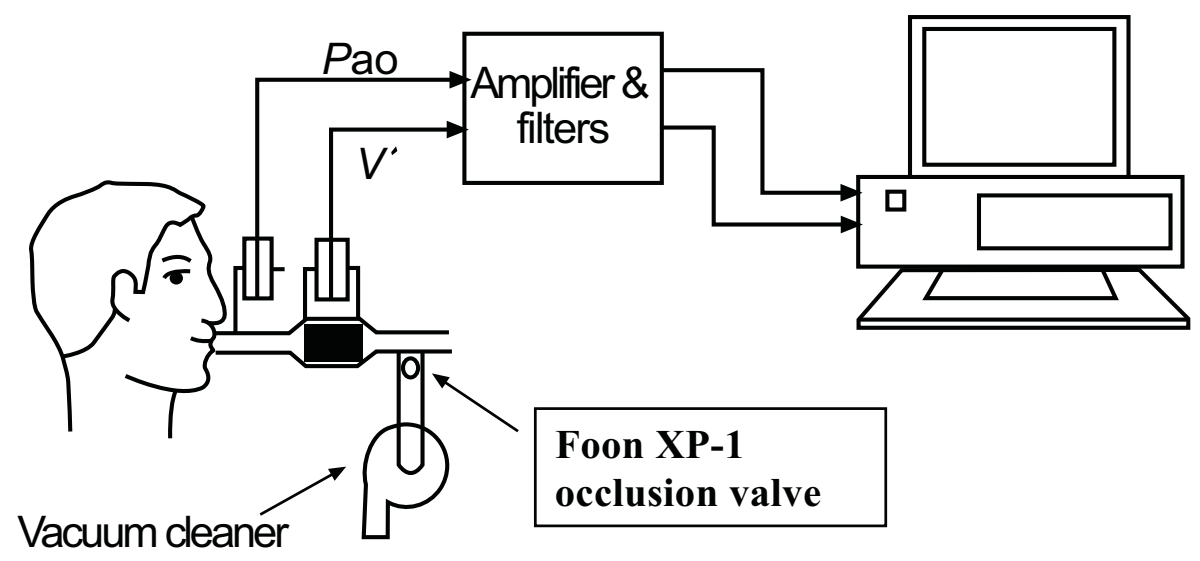

Fig. (1). Diagram of negative expiratory pressure (NEP) apparatus. Pao, airway pressure; V', flow. See text for details. 
subject underwent a 3 min trial run in order to become accustomed to the procedure. Data acquisition began after regular breathing was achieved. NEP was applied throughout expiration for a series of 10 to 15 single breaths. As suggested by Ferretti et al. [20], to increase discrimination between cohorts, we used NEPs less than commonly reported (-2 to $-3 \mathrm{~cm} \mathrm{H}_{2} \mathrm{O}$ instead of -5 to $-10 \mathrm{~cm} \mathrm{H}_{2} \mathrm{O}$ ) [7-9, $12-14]$. Each test breath was followed by a 20 - to 30 -s period of regular breathing. These serial maneuvers were repeated with the subject lying on a comfortable gurney with head resting on a low pillow. Subjects were monitored for leaks at the mouthpiece. A closed system ensured that after the NEP tests the end-expiratory volume returned to the pre-NEP level, an important criterion for NEP breath analysis. Inspection of the breaths for this requirement ensured that 10 breaths from each set of breaths were acceptable for analysis. Coefficients of variation for intraindividual tidal volume
$(\mathrm{Vt})$, inspiratory time (Ti), and expiratory time (Te) were $5 \%-12 \%$ in both postures, as reported for normals and COPD [26-28].

\section{Assessment of EFL}

The expiratory flow-volume loops generated during application of NEP were compared by superimposition on those obtained during the immediately preceding breath (Fig. 2). After application of NEP, expiratory flow either increased above control flow throughout expiration, reflecting absence of EFL (Fig. 3), did not change from control, consistent with intrathoracic airway obstruction (Fig. 4), or decreased transiently $(<30 \%$ control Vt span) (Fig. 7) or in a sustained manner ( $\geq 30 \% \mathrm{Vt}$ span, two examples, Figs. $5,6)$ throughout expiration reflecting, respectively, transient or sustained upper airway collapse [7-9, 12-14]. The term EFL used here encompasses all the types of flow limitation

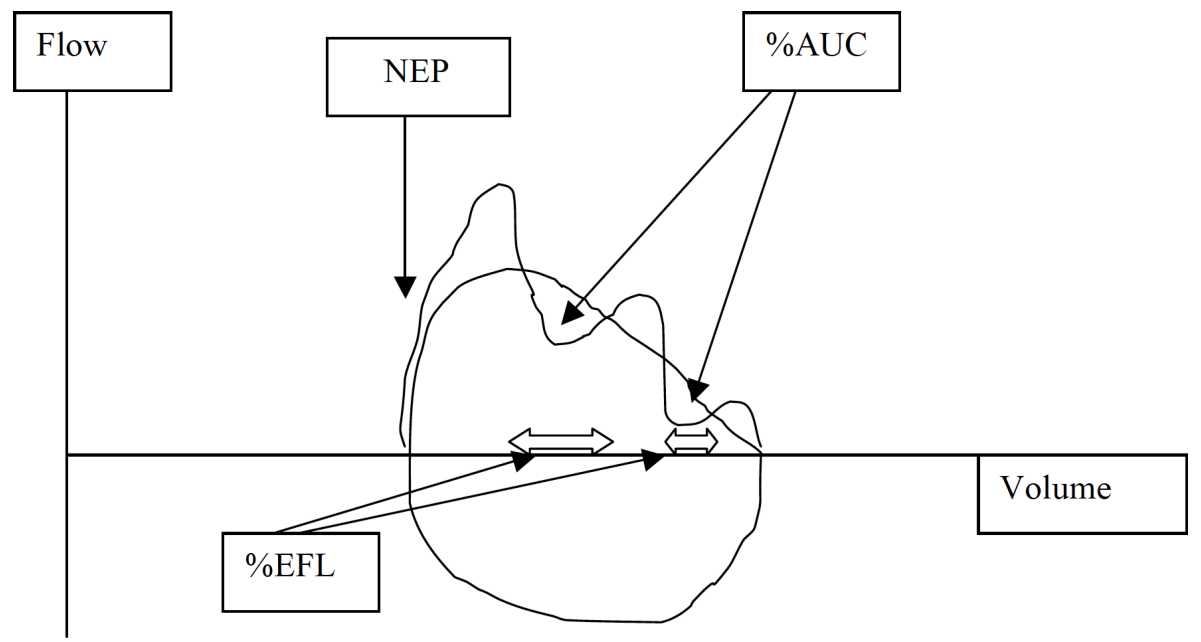

Fig. (2). Diagram of computations of \%EFL and \%AUC. NEP, negative expiratory pressure; EFL, expiratory flow limitation; \%AUC, percent area of control expiratory curve occupied by the NEP curve. See text for details.

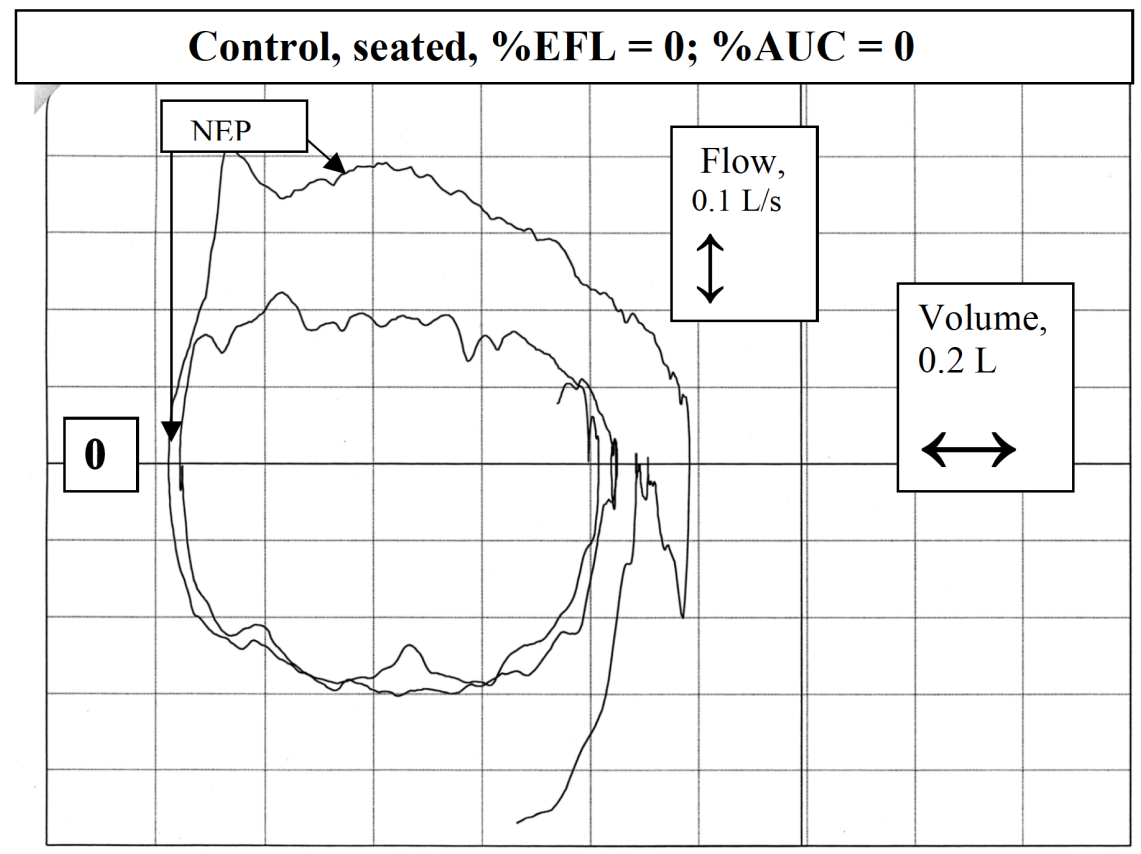

Fig. (3). Tidal and NEP curves in a control subject in seated position. Note how the expiratory flow increases above control flow upon application of NEP. 


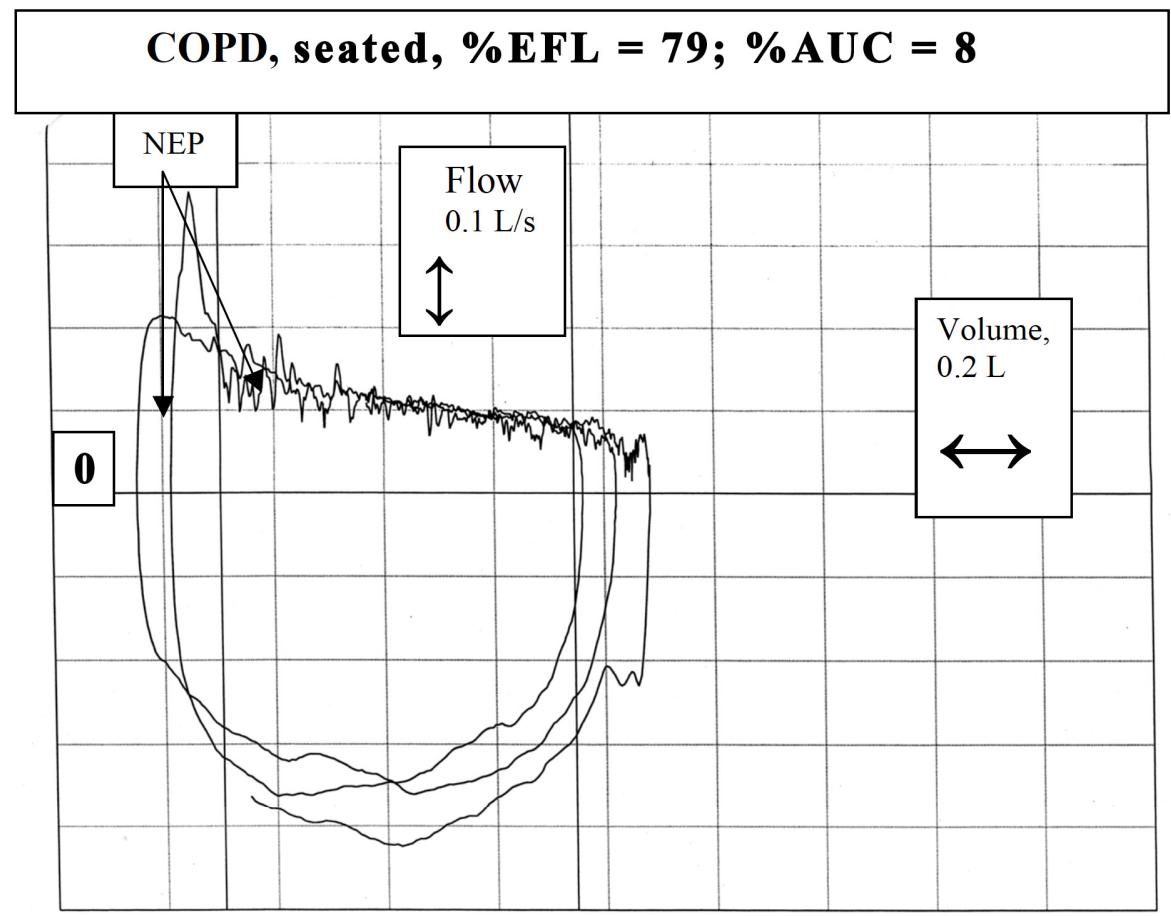

Fig. (4). Example of a subject with severe chronic obstructive pulmonary disease in supine posture exhibiting sustained absence in change of flow.

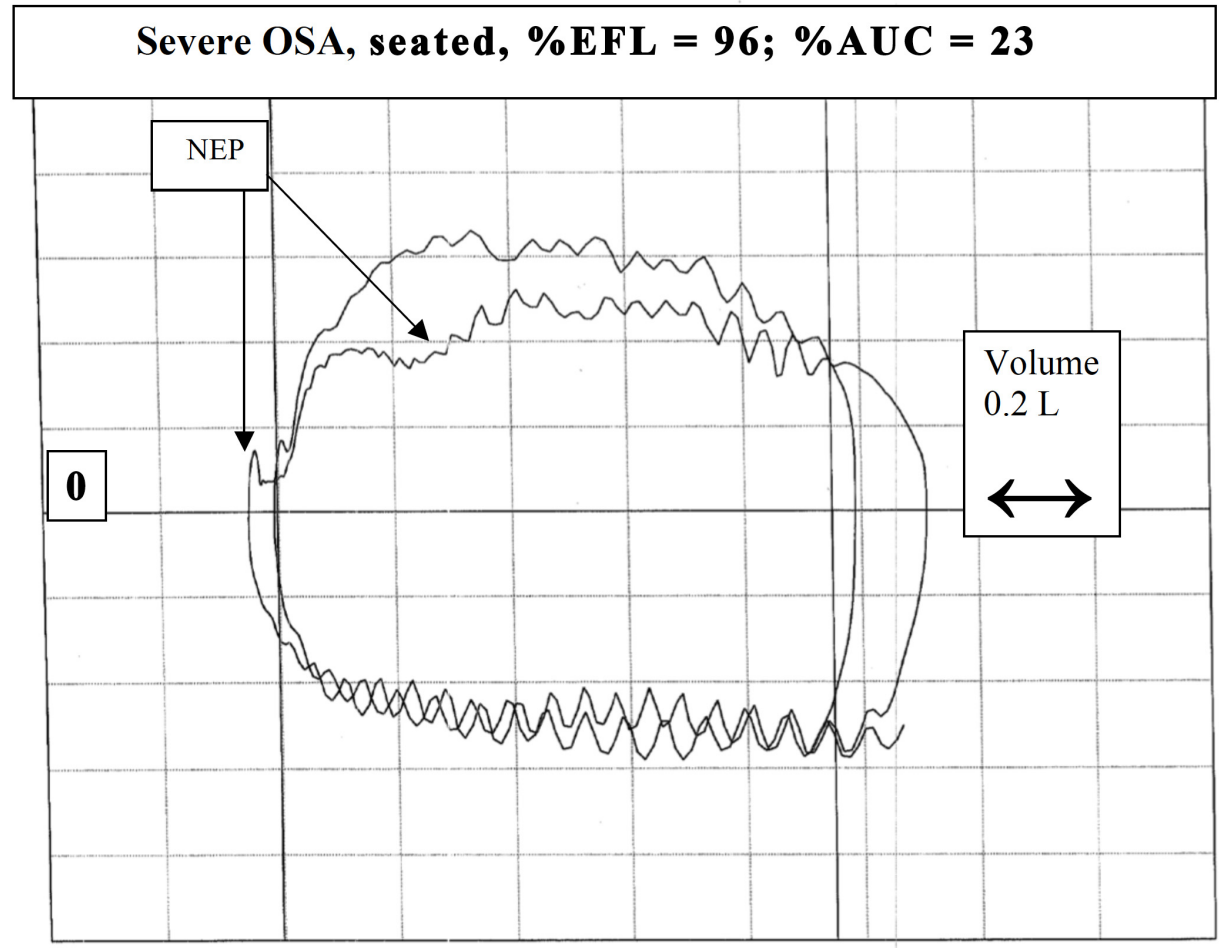

Fig. (5). Example of a subject with obstructive sleep apnea exhibiting sustained decrease in flow ( $>30 \% \mathrm{Vt})$ below control in seated position. Note the "sawtooth" pattern in both the control and NEP breaths during inspiration and expiration.

described, and is broader than the original definition of tidal EFL (i.e., absence of change in expiratory flow) as defined by Koulouris et al. [5].

EFL was computed by the following methods (Fig. 2):

1. EFL was expressed as percentage of the expired tidal volume over which the NEP-induced flow did not exceed spontaneous flow (\%EFL) $[5,6]$ for each subject in both postures as the median of 10 acceptable NEP breaths.

2. The degree to which the expiratory curve during NEP decreased below the preceding control expiratory curve was expressed as the percentage of the area 
under the control curve (\%AUC), based on a modification of Tamisier et al. [14]. This value was expressed as the median of the same10 acceptable NEP breaths in each posture.

3. To further enhance discrimination between COPD and OSA, we computed the ratio \%AUC/\%EFL because changes in \%EFL and \%AUC were not always of the same magnitude or direction. Thus, an increase \%AUC/\%EFL would indicate a greater degree of upper airway FL than intrathoracic EFL, while a decrease with preservation of \%EFL would be more consistent with intrathoracic EFL. This new index was expressed as an arbitrary unit, as the median of the same 10 acceptable NEP breaths in each posture.

\section{Statistical Analysis}

Because the data exhibited skewed distributions for many of the lung function variables, nonparametric statistical procedures were used [29]. Intragroup medians and ranges were used where there were outlier values. These values were depicted as notched bar and whisker plots in order to highlight more clearly the significance in differences between cohorts. The notches surrounding the medians provide a measure of the rough significance of differences between the values. Specifically, if the notches about two medians do not overlap in this display, the medians are significantly different at about a $95 \%$ confidence level [30]. For each of the variables investigated, the Kruskal-Wallis test (a non-parametric version of analysis of variance) was employed to assess differences in central tendency between subjects with non-OSA obesity, mild-moderate and severe obstructive sleep apnea, COPD, and control subjects. In order to perform similar analyses adjusting for age and gender, general linear models were used to model the ranks of test variables as a function of age, gender and cohort. The Wilcoxon signed rank test (a nonparametric analog of the paired-sample t-test) was used to test for differences between variables obtained in the seated and supine postures. The Pvalues for multiple comparisons amongst cohorts for each body position were adjusted by the Tukey-Kramer method.

\section{RESULTS}

\section{Anthropometric and Respiratory Function Data}

Of 145 patients screened, excluded from analysis were 5 patients with asthma (according to ATS/ERS criteria), and one with congestive heart failure. The remaining 139 subjects consisted of 50 patients with documented OSA [ 26 mild-moderate (AHI 5-30), 24 severe (AHI >30)], 28 with non-OSA obesity, 42 with COPD, and 19 non-smoking healthy subjects (Table 1). The non-obese, mild-moderate OSA and severe OSA patients were well-matched in age, but the COPD patients were older, while the control subjects were younger. The BMIs of the non-OSA obese, the mildmoderate and severe OSA cohorts were, respectively, $62 \%$, $63 \%$ and $87 \%$ greater than in the control subjects. $\mathrm{FEV}_{1}$ in the non-OSA obese, OSA (mild-moderate), OSA (severe), and COPD subjects was $10 \%, 15 \%, 27 \%$ and $54 \%$ less, respectively, than in the controls (all statistically significant). The AHI in the severe OSA patients was, respectively, 47 and 3.8 times greater than in the obese and mild-moderate OSA groups.

\section{Expiratory Flow Limitation}

Fig. (8) shows that median \%EFL in the severe OSA and COPD groups was, respectively, 2.6 and 3.5 times larger than the controls in supine position (severe OSA vs control: $\mathrm{P}=0.001$; COPD $v s$ control: $\mathrm{P}=0.001$ ), and 2.9 and 4.4 times larger, respectively, than in the controls in the seated position (severe OSA $v s$ control: $\mathrm{P}=0.01$; COPD $v s$ control: $\mathrm{P}=0.007$ ), adjusted for age and gender.

There were no significant differences in \%AUC amongst cohorts (not shown). Fig. (9) shows that the mild-moderate OSA patients tended to exhibit the highest value of $\% A U C / \% E F L$ of all cohorts in seated posture, but this value was significantly different from only that of the COPD cohort (2.2 times higher than the COPD group, $\mathrm{P}=0.04$ ). Otherwise, \%AUC/\%EFL did not differ significantly amongst cohorts because of spread in individual values.

Most subjects exhibited a transient decrease in flow in occasional NEP curves, mainly while in the supine posture. A sustained absence of change in flow in NEP breaths was

Table 1. Anthropometric and Physiologic Data for Patients with Non-Obesity, Obstructive Sleep Apnea (OSA, Mild-Moderate, Severe), COPD and Control Subjects

\begin{tabular}{|c|c|c|c|c|c|c|}
\hline & Obese, Non-OSA & OSA, Mild-Moderate & OSA, Severe & COPD & Controls & P-Value $\dagger$ \\
\hline No. subjects & 28 & 26 & 24 & 42 & 19 & \\
\hline Age (yr) & $48.0(10.6)$ & $52.1(9.8)$ & $51.3(9.2)$ & $62.0(9.8)$ & $44.3(11.8)$ & $<0.0001$ \\
\hline $\operatorname{Sex}(F / M)$ & $19 / 9$ & $14 / 12$ & $10 / 14$ & $11 / 31$ & $10 / 9$ & 0.01 \\
\hline BMI $\left(\mathrm{kg} / \mathrm{m}^{2)}\right.$ & $40.1(6.6)$ & $40.3(8.8)$ & $46.4(7.5)$ & $28.2(6.5)$ & $24.8(3.7)$ & $<0.0001$ \\
\hline FVC \% (pred) & $90.4(14.2)$ & $84.7(17.9)$ & $75.7(20.7)$ & $75.0(20.0)$ & $100.3(12.9)$ & $<0.001$ \\
\hline $\mathrm{FEV}_{1} \%($ pred $)$ & $98.2(15.6)$ & $93.0(17.9)$ & $79.9(24.2)$ & $49.8(18.8)$ & $109.1(12.9)$ & $<0.0001$ \\
\hline $\mathrm{FEV}_{1} / \mathrm{FVC}(\%)$ & $82.0(7.3)$ & $82.2(6.0)$ & $78.9(8.7)$ & $46.9(12.9)$ & $83.2(5.3)$ & $<0.0001$ \\
\hline TLC (\% pred) & $97.3(10.5)$ & $92.3(13.4)$ & $89.3(17.1)$ & $102.9(21.9)$ & $99.3(9.2)$ & 0.02 \\
\hline AHI (events/hr) & $1.2(1.4)$ & $14.8(6.5)$ & $55.9(20.5)$ & & & $<0.0001$ \\
\hline
\end{tabular}

Values are expressed as means (SD).

$\uparrow$ ANOVA across all cohorts, except chi square for sex. 


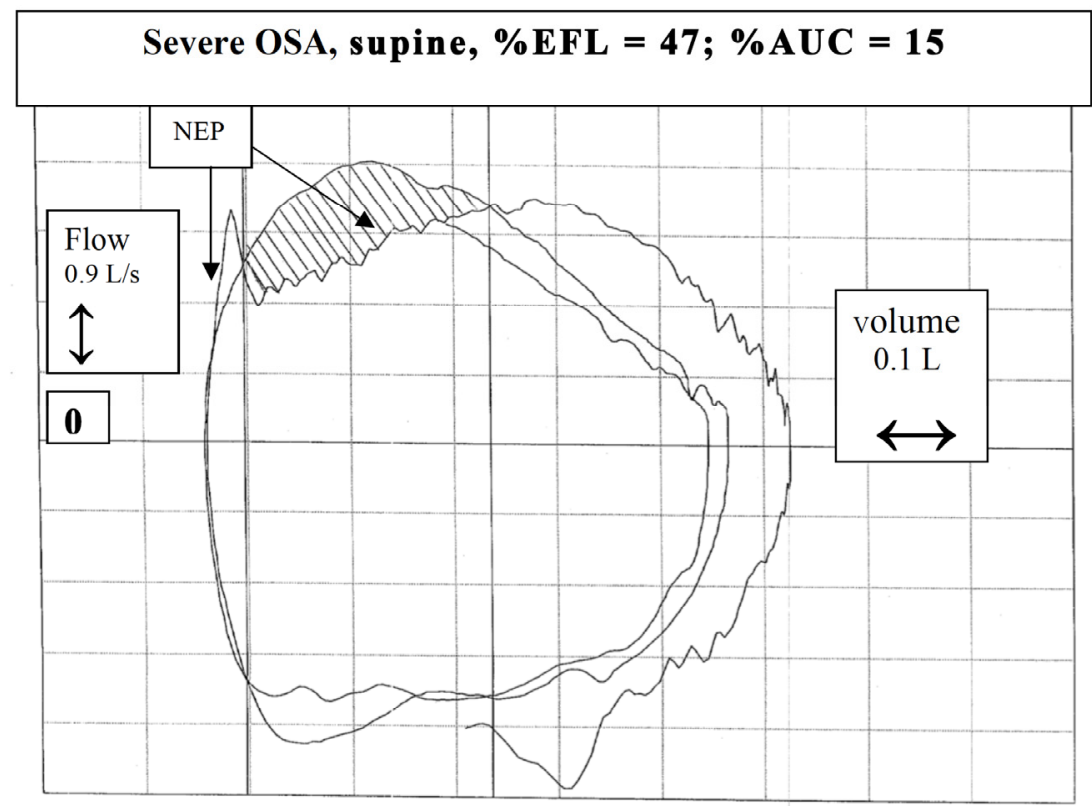

Fig. (6). Another example of a patient with severe OSA in supine posture. In this case, the decrease in flow with NEP was less sustained, although still $>30 \% \mathrm{Vt}$.

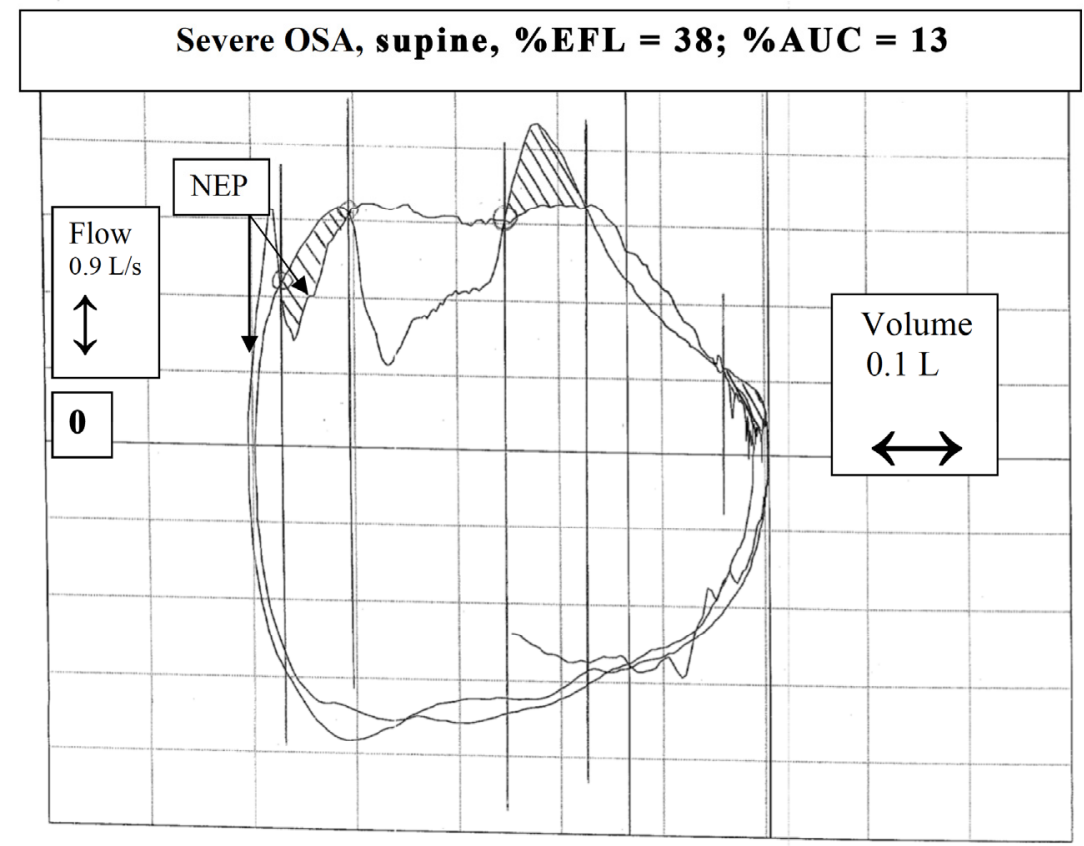

Fig. (7). Another example of a patient with severe OSA in supine posture. In this case, application of NEP resulted in both a transient $(<30 \%$ $\mathrm{Vt}$ ) decrease and transient increase in flow. Note that the patient exhibited a transient decrease in expiratory flow during the control tidal breath even without application of NEP (note the dip in the central portion of the control tidal expiration).

primarily observed in COPD patients, consistent with intrathoracic flow limitation. Twelve of 17 seated and 22 of 25 supine COPD patients (mean $\mathrm{FEV}_{1}$ 54\% predicted) exhibiting sustained decreases in flow below control in occasional NEP breaths had BMIs $\geq 30$. Their median $\%$ EFL, $\%$ AUC and \%AUC/\%EFL, however, did not differ significantly from the main COPD cohort. Two control subjects, aged 65 and 61 years, exhibited sustained absence of change in flow in occasional NEP breaths in both postures. Two other control subjects with transient decrease in flow during occasional NEP breaths in supine posture had BMIs just below the threshold for obesity (29.58 and 29.9).

\section{DISCUSSION}

To our knowledge, this study is the first to quantitatively compare EFL in patients with COPD, non-OSA obesity and OSA in seated and supine postures. The main findings are:

1. COPD patients exhibited the highest \%EFL in seated posture, consistent with intrathoracic flow limitation. Percent EFL significantly increased in the OSA groups and tended to increase in the other cohorts upon assuming the supine position.

2. While seated, when compared to other cohorts, OSA patients exhibited a greater tendency to upper airway 


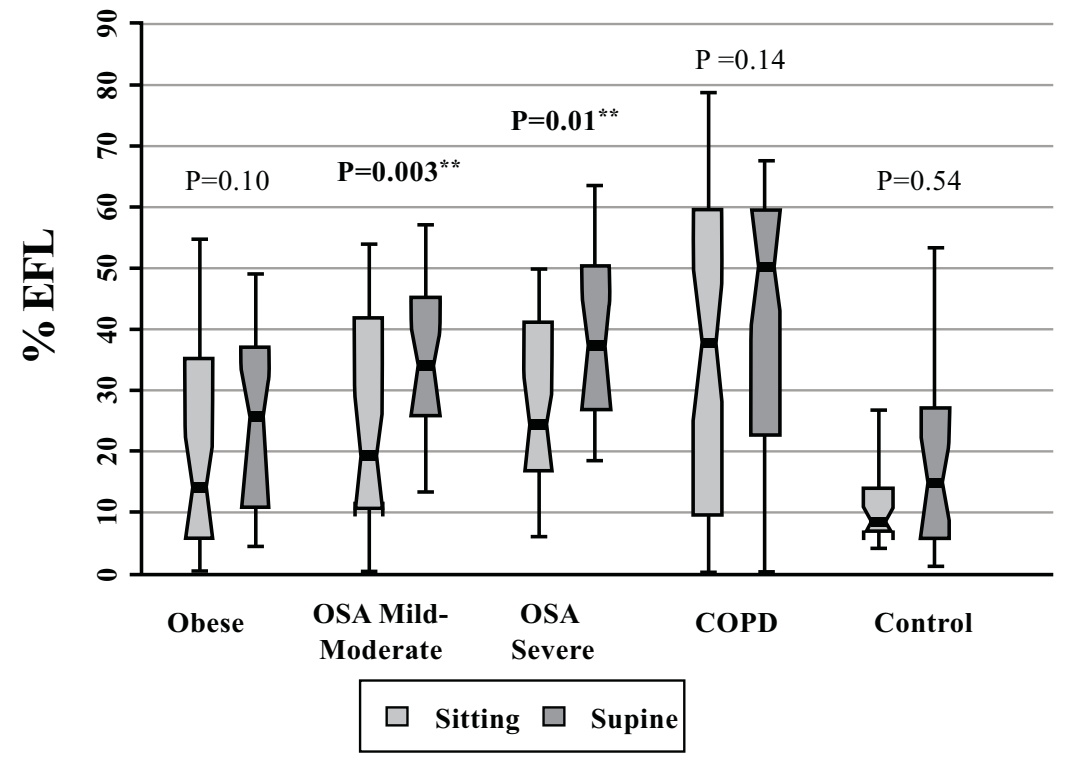

Fig. (8). Expiratory Flow Limitation (\% EFL) Data for Patients with Obesity Alone, Obstructive Sleep Apnea (OSA, mild-moderate, severe), COPD, and Control Subjects. Each notched box represents the 25th-75th percentile; internal line indicates the median; whiskers indicate the 10 th and 90th percentiles. Notches extend to $+/-1.58$ inter-quartile range/sqrt (sample size). Notches that do not overlap suggest strong evidence of different medians. The general linear model used to model the ranks of the test variable as a function of the sitting and supine groups, adjusted for age and sex, showed significant differences amongst cohorts in the sitting posture, $\mathrm{P}=0.05$, and amongst cohorts in the supine posture, $\mathrm{P}=0.005$. $* *$ Wilcoxon signed rank test (non-parametric paired-sample t-test) for comparisons between sitting and supine positions in each cohort.

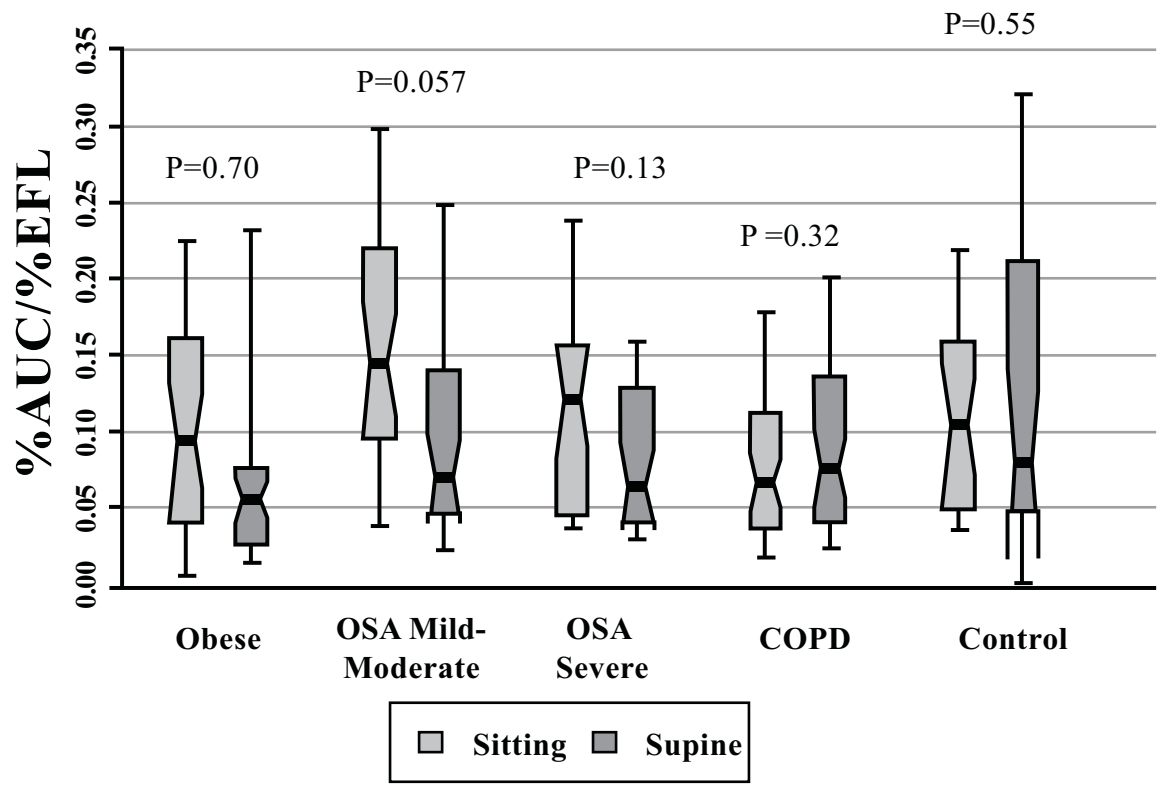

Fig. (9). \%AUC/\%EFL for patients with obesity alone, obstructive sleep apnea (OSA, mild-moderate, severe), COPD, and control subjects. Each notched box represents the 25th-75th percentile; internal line indicates the median; whiskers indicate the 10th and 90th percentiles. Notches extend to $+/-1.58$ inter-quartile range/sqrt(sample size). Notches that do not overlap suggest strong evidence of different medians. The general linear model used to model the ranks of the test variable as a function of the sitting and supine groups, adjusted for age and sex, showed that the mild-moderate OSA patients exhibited the highest value of all cohorts in seated posture (significantly different from the seated COPD cohort only, $\mathrm{P}=0.04$ ). There was no significant difference between sitting or supine position in any cohort [Wilcoxon signed rank test (non-parametric paired-sample t-test) for comparisons between sitting and supine positions in each cohort].

collapsibility as evidenced by higher \%AUC and $\%$ AUC/\%EFL values, although median values exhibited a spread of individual values that prevented differences between cohorts from being significant. In supine posture, COPD patients exhibited the greatest $\%$ AUC but not $\%$ AUC $\%$ EFL.
3. The \%AUC method was able to only differentiate COPD patients from those with mild-moderate OSA in the seated position.

An increase in the \%AUC and \%AUC/\%EFL reflects a greater degree of extrathoracic airflow limitation (as occurs 
in obese and OSA subjects) while an increase in \%EFL in the absence of an increase in \%AUC indicates the presence of intrathoracic flow limitation (as in COPD). Thus, subjects with greater increases in the $\% \mathrm{AUC} / \% \mathrm{EFL}$ than in the $\%$ EFL upon assuming supine posture develop an increase in upper airway resistance rather than intrathoracic airflow limitation. At the same time, in patients with COPD, intrathoracic airflow limitation may increase in supine position (as exhibited by an increase in \%EFL), a finding more likely to occur as FEV1 decreases.

\section{Percent EFL}

We confirmed the usefulness of the NEP technique to assess upper airway collapsibility as shown previously [7-9, 12-14, 28, 31-34]. Moreover, our findings of higher \%EFL in COPD compared to controls confirm findings of previous studies [5, 7, 28, 29]. Our finding of variability in measurements using the NEP technique was also reported by Walker et al. [35] and Hadcroft and Calverley [36] and is likely due to a number of factors, discussed below.

\section{Percent AUC}

Percent AUC tended to be greater in seated OSA patients indicating that mechanisms maintaining upper airway patency while supine were operational. By contrast, \%AUC was greatest in supine COPD patients, almost double its seated median. Thus, mechanisms preserving patency in supine COPD patients may not be as effective as in obese or OSA individuals. Reductions in lung volume (as occur in supine posture) cause decreases in caudal traction on the upper airway and concomitant increases in upper airway collapsibility [37-40]. Furthermore, supine positioning promotes laryngeal edema and upper airway narrowing [4042]. In COPD, mobilization of secretions when supine may have contributed to this finding. Yet, the finding of an overall increase in $\% \mathrm{EFL}$ in supine position without concomitant increases in \%AUC (or \% AUC/\%EFL) in most cohorts indicates a greater degree of intrathoracic tidal EFL [as defined by Koulouris et al. [5] than extrathoracic FL. This is likely related to decrease in lung volume in supine posture.

Some explanations for the inconsistent findings: During early expiration, there is post-inspiratory inspiratory activity (PIIA) which may counteract the effect of NEP. At the beginning of expiration, PIIA may oppose NEP [resistance posed by pliometric contraction (= lengthening) of the inspiratory muscles] [43]. This implies that NEP should not be applied too early in expiration (when PIIA is high). In our subjects, NEP was applied immediately after the onset of expiratory flow so that PIIA is likely to have influenced heterogeneity of EFL within cohorts.

Our method for computing \%AUC is similar to that of Tamisier et al. [14] who devised a quantitative index corresponding to the ratio of the area under the expiratory flow-volume curves between NEP and control tidal volume. They did not, however, study subjects with mild OSA (BMI 5-15), and the age of their controls was somewhat younger (mean 34 years). They also applied NEP near end-expiratory volume which stimulates activation of the genioglossus [3, 44]. This can alter the area under the terminal portion of the
NEP curve, affecting the quantitative index used to assess the upper airway collapsibility. Our results suggest that obese and OSA patients are more likely to experience upper airway narrowing while seated than COPD patients, indicating reduced PIIA and genioglossus activity in that posture. The severe OSA patient shown in Fig. (5) exhibited abolition of "sawtoothing" and modest decreases in \%EFL and \%AUC while supine, consistent with increased PIIA and genioglossus activity. Two control subjects exhibited EFL (with absence of change in tidal flow in some NEP breaths) in both postures; both were in their $60 \mathrm{~s}$ and did not experience dyspnea. Expiratory flow limitation is known to occur in some older patients, even in the presence of normal $\mathrm{FEV}_{1} / \mathrm{FVC}$ and absence of dyspnea [28].

These considerations raise a potential limitation in our methods. Our study and those of others [7-9, 12-14, 28, 3133] are based on the assumption that upper airway collapsibility can be identified only when expiratory flow during NEP decreases below the control curve. However, pharyngeal collapse can also occur with a smaller increase in expiratory flow during NEP [20]. Thus, detecting upper airway collapsibility only by computing the span of the preceding control tidal volume over which the NEP curve drops below the control breath can be misleading. It is possible that some patients with upper airway collapsibility may not have been identified if they exhibited only a reduction in the increase of expiratory flow during NEP. However, since we were primarily interested in discriminating patients with COPD from those with obesity and OSA, the same methods for quantifying EFL were used in all cohorts.

Another limitation in our study was that sleep studies were not obtained in our COPD patients and controls. Sleeprelated disordered breathing (SDB) and nocturnal desaturations have been reported in COPD patients, giving rise to an "overlap syndrome" although not all SDB could be classified as frank sleep apnea $[45,46]$. We were careful, however, in excluding subjects with symptoms of sleep apnea in both cohorts. None of the obese COPD patients gave a history of snoring or symptoms of sleep apnea.

In conclusion, the \%EFL and \%AUC methods are useful in determining the magnitude of intrathoracic or extrathoracic FL in patients with COPD and OSA, but fail to distinguish cohorts on the basis of EFL quantification using the area under the curve method because of interindividual variabilities. Pattern recognition of NEP tracings remains the best way to distinguish intrathoracic from extrathoracic EFL.

\section{FINANCIAL/NONFINANCIAL DISCLOSURES}

The authors have reported that no potential conflicts of interest exist with any companies/organizations whose products or services may be discussed in this article.

\section{ACKNOWLEDGEMENTS}

Author contributions: Dr. Baydur contributed to the formulation of the scientific problem and study concept, methodology design, planning and conduct; screening and recruiting of most of the subjects; conducted all of the experiments and collated most of the data; approval of the study proposal and final version of the manuscript. 
Dr. Vigen and Dr. Chen provided critical statistical outcome and data analysis.

Other contributions: The authors thank Dr. Joseph Milic-Emili for valuable input to the manuscript; Mr. Louis Wilkinson for his valuable technical assistance; Dr. Danielle Kushner and Mr. Shadman Chowdhury for assistance in tabulating data. The authors also thank the technical staff of the Pulmonary Function Laboratory at Los Angeles County + University of Southern California Medical Center for performing the lung function and polysomnographic testing, and all the patients and volunteers who participated in the study.
ABBREVIATIONS
AHI $=$ Apnea-hypopnea index
AUC $=$ Area under control curve enclosed by the NEP curve
BMI $=$ Body mass index
$\mathrm{EFL}=$ Expiratory flow limitation
$\mathrm{FEV}_{1}=$ Forced expiratory volume in the first second
FRC $=$ Functional residual capacity
$\mathrm{FVC}=$ Forced vital capacity
AUC $=$ Area under NEP curve
NEP $=$ Negative expiratory pressure
OSA $=$ Obstructive sleep apnea
PIIA $=$ Post-inspiratory inspiratory activity
$\mathrm{Vt}=$ Tidal volume
$\mathrm{Ti}=$ Inspiratory time
$\mathrm{Te}=$ Expiratory time
TLC = Total lung capacity
ANOVA $=$ Analysis of variance

\section{REFERENCES}

[1] Gleadhill IC, Schwartz AR, Schubert N, et al. Upper airway collapsibility in snorers and in patients with obstructive hypopnea and apnea. Am Rev Respir Dis 1991; 143: 1300-3.

[2] Berg S, Cole P, Hoffstein V, et al. Upper airway pressures in snorers and nonsnorers during wakefulness and sleep. J Otolaryngol 2001; 30: 69-74.

[3] Suratt PM, White DP. Evaluations of the upper airway in patients with obstructive apnea. Sleep 1991; 14: 361-71.

[4] Brown IG, Bradley TD, Phillipson EA, Zamel N, Hoffstein V. Pharyngeal compliance in snoring subjects with and without obstructive sleep apnea. Am J Rev Respir Dis 1985; 132: 211-5.

[5] Koulouris NG, Valta P, Lavoie A, et al. A simple method to detect expiratory flow limitation during spontaneous breathing. Am J Respir Crit Care Med 1994; 149: 352-57.

[6] Valta P, Corbeil C, Lavoie A, et al. Detection of expiratory flow limitation during mechanical ventilation. Am J Respir Crit Care Med 1994; 154: 1726-34.

[7] Baydur A, Wilkinson L, Mehdian R, Bains B, Milic-Emili J. Extrathoracic expiratory flow limitation in obesity and obstructive and restrictive disorders. Chest 2004; 125: 98-105.

[8] Van Meerhaeghe A, Delpire P, Stenuit P, Kerkhofs M. Operating characteristics of the negative expiratory pressure technique in predicting obstructive sleep apnoea syndrome in snoring patients. Thorax 2004; 59: 883-8.

[9] Liistro G, Veriter C, Dury M, et al. Expiratory flow-limitation in awake sleep-disordered breathing subjects. Eur Respir J 1999; 14: $185-90$.
[10] Koulouris NG, Hardavella G. Physiological techniques for detecting expiratory flow limitation during tidal breathing. Eur Respir J 2011; 20: 147-55.

[11] Eltayara L, Becklake MR, Volta CA, Milic-Emili J. Relationship between chronic dyspnea and expiratory flow limitation in patients with chronic obstructive pulmonary disease. Am J Respir Crit Care Med 1996; 154: 1726-34.

[12] Verin E, Tardif C, Portier F, et al. Evidence for expiratory flow limitation of extrathoracic origin in patients with obstructive sleep apnoea. Thorax 2002; 57: 423-8.

[13] Tantucci C, Duguet A, Ferretti A, et al. Effect of negative expiratory pressure on respiratory system flow resistance in awake snorers and nonsnorers. J Appl Physiol 1999; 87: 969-76.

[14] Tamisier R, Wuyam B, Nicolle I, et al. Awake flow limitation with negative expiratory pressure in sleep disordered breathing. Sleep Med 2005; 6: 205-13.

[15] Romano S, Salvaggio A, Hirata RP, et al. Upper airway collapsibility evaluated by a negative expiratory pressure test in severe obstructive sleep apnea. Clinics (Sao Paulo) 2011; 66: 56772.

[16] Guillot M, Costes F, Sforza E, et al. Is tidal expiratory flow limitation predictive of sleep-related disorders in the elderly? Eur Respir J 2010; 36: 842-8.

[17] Lin C-K, Lin C-C. Work of breathing and respiratory drive in obesity. Respirology 2012; 17: 402-11.

[18] Pellegrino R, Viegi G, Brusasco V, et al. Interpretative strategies for lung function tests. Eur Respir J 2005; 26: 948-68.

[19] American Academy of Sleep Medicine Task Force. Sleep-related breathing disorders in adults: recommendations for syndrome definition and measurement techniques in clinical research. Sleep 1999; 22: 667-89.

[20] Ferretti A, Giampiccolo P, Redolfi S, et al. Upper airway dynamics during negative expiratory pressure in apneic and non-apneic awake snorers. Respir Res 2006; 7: 54-64.

[21] Obesity: preventing and managing the global epidemic; report of a WHO consultation on obesity. Geneva, Switzerland: World Health Organization 1997.

[22] Baydur A, Vigen C, Chen Z, Wilkinson L, Milic-Emili J. Expiratory flow limitation (EFL) in obstructive sleep apnea (OSA) and other respiratory disorders: Comparison of three analyses using negative expiratory pressure (NEP) method. Am J Respir Crit Care Med 2009; 179: A6067.

[23] Schoenberg JB, Beck GJ, Bouhuys A. Growth and decay of pulmonary function in healthy blacks and whites. Respir Physiol 1978; 33: 367-93.

[24] Crapo RO, Morris AH, Clayton PD, et al. Lung volumes in healthy nonsmoking adults. Bull Eur Physiopathol Respir 1982; 18: 41925.

[25] Farré R, Navajas D, Peslin R, et al. A correction procedure for the asymmetry of differential pressure transducers in respiratory impedance measurements. IEEE Trans Biomed Eng 1989; 136: 1137-40.

[26] Sorli J, Grassino A, Lorange G, et al. Control of breathing in patients with chronic obstructive lung disease. Clin Sci Mol Med 1978; 54: 295-304.

[27] Aubier M, Murciano D, Fornier M, et al. Central respiratory drive in acute respiratory failure of patients with chronic obstructive pulmonary disease. Am Rev Respir Dis 1980; 122: 191-9.

[28] de Bisschop C, Marty ML, Tessier JF, et al. Expiratory flow limitation and obstruction in the elderly. Eur Respir J 2005; 26: 594-601.

[29] Dixon WJ, Massey FJ Jr. Introduction to statistical analysis, $4^{\text {th }}$ ed. New York: McGraw-Hill 1983; pp. 385-414.

[30] McGill R, Tukey JW, Larsen WA. Variations of box plots. Am Stat 1978; 32: 12-6.

[31] Ferretti A, Giampiccolo P, Cavalli A, Milic-Emili J, Tantucci C. Expiratory flow limitation and orthopnea in massively obese subjects. Chest 2001; 119: 1401-8.

[32] Insalaco G, Romano S, Marrone O, Salvaggio A, Bonsignore G. A new method of negative expiratory pressure test analysis detecting upper airway flow limitation to reveal obstructive sleep apnea. Chest 2005; 128: 2159-65.

[33] Rouatbi S, Tabka Z, Dogui M, Abdelghani A, Guénard H. Negative expiratory pressure (NEP) parameters can predict obstructive sleep apnea syndrome in snoring patients. Lung 2009; 187: 23-8. 
[34] Baydur A, Milic-Emili J. Expiratory flow limitation during spontaneous breathing. Chest 1997; 112: 1017-23.

[35] Walker R, Paratz J, Holland AE. Reproducibility of the negative expiratory pressure technique in COPD. Chest 2007; 132: 471-6.

[36] Hadcroft J, Calverley PMA. Alternative methods for assessing bronchodilator reversibility in chronic obstructive pulmonary disease. Thorax 2001; 56: 713-20.

[37] Thut DC, Schwartz AR, Roach D, Wise RA, Permutt S, Smith PL. Tracheal and neck position influence upper airway flow dynamics by altering airway length. J Appl Physiol 1993; 75: 2084-90.

[38] Van de Graaff WB. Thoracic traction on the trachea: mechanisms and magnitude. J Appl Physiol 1991; 70: 1328-36.

[39] Squire SB, Patil SP, Schneider H, Kirkness JP, Smith PL. Effect of end-expiratory lung volume on upper airway collapsibility in sleeping men and women. J Appl Physiol 2010; 109: 977-85.

[40] Owens RL, Malhotra A, Eckert DJ, White DP, Jordan AS. The influence of end-expiratory lung volume on measurements of pharyngeal collapsibility. J Appl Physiol 2010; 108: 445-51.
[41] Shepard JW Jr, Pevernagie DA, Stanson AW, et al. Effects of changes in central venous pressure on upper airway size in patients with obstructive sleep apnea. Am J Respir Crit Care Med 1996; 153: 250-4.

[42] Jafari B, Mohsenin V. Overnight rostral fluid shift in obstructive apnea. Chest 2011; 140: 991-7.

[43] Shee CD, Ploy-song-sang Y, Milic-Emili J. Decay of inspiratory muscle pressure during expiration in conscious humans. J Appl Physiol 1985; 58: 1859-65.

[44] Tantucci C, Mehiri S, Duguet A, et al. Application of negative expiratory pressure during expiration and activity of genioglossus in humans. J Appl Physiol 1998; 84: 1076-82.

[45] Caterall JR, Douglas NJ, Calverley PM, et al. Transient hypoxemia during sleep in chronic obstructive pulmonary disease is not a sleep apnea syndrome. Am Rev Respir Dis 1983; 126: 206-10.

[46] Aoki T, Ebihara A, Salamaki F, et al. Sleep disordered breathing in patients with chronic obstructive disease. COPD 2005; 2: 243-52.

Received: June 1, 2012

Revised: June 29, 2012

Accepted: August 13, 2012

(C) Baydur et al.; Licensee Bentham Open.

This is an open access article licensed under the terms of the Creative Commons Attribution Non-Commercial License (http://creativecommons.org/licenses/by-nc/3.0/) which permits unrestricted, non-commercial use, distribution and reproduction in any medium, provided the work is properly cited. 